\title{
RAZPRAVE
}

\section{PROSTORSKO UMEŠČANJE IN ŠIRITVE KMETIJ V SLOVENIJI: ZAKONODAJNI OKVIR IN IZKUŠNJE SLOVENSKIH OBČIN}

\author{
AVTORJI \\ dr. Nika Razpotnik Visković \\ Znanstvenoraziskovalni center Slovenske akademije znanosti in umetnosti, Geografski inštitut Antona Melika, \\ Gosposka ulica 13, SI - 1000 Ljubljana, Slovenija \\ nika.razpotnik@zrc-sazu.si
}

\section{dr. Primož Pipan}

Znanstvenoraziskovalni center Slovenske akademije znanosti in umetnosti, Geografski inštitut Antona Melika, Gosposka ulica 13, SI - 1000 Ljubljana, Slovenija

primoz.pipan@zrc-sazu.si

\section{dr. Damjana Gantar}

Urbanistični inštitut Republike Slovenije, Trnovski pristan 2, SI - 1000 Ljubljana, Slovenija

damjana.gantar@uirs.si

\section{mag. Ina Šuklje Erjavec}

Urbanistični inštitut Republike Slovenije, Trnovski pristan 2, SI - 1000 Ljubljana, Slovenija

ina.suklje-erjavec@uirs.si

DOI: $10.3986 / G V 89102$

UDK: 711.3:631.111(497.4)

COBISS: 1.01

\section{IZVLEČEK}

Prostorsko umeščanje in širitve kmetij v Sloveniji: zakonodajni okvir in izkušnje slovenskih občin Namen prispevka je kritičen pregled obstoječih raziskav in zakonodaje v povezavi z umeščanjem kmetij $v$ prostor ter analiziranje izkušenj, s katerimi se soočajo prostorski načrtovalci v slovenskih občinah. Analiza je rezultat obsežne raziskave o umeščanju kmetijskih objektov v prostor in reševanju s tem povezanih konfliktov, na podlagi izkušenj 190 slovenskih občin. S pomočjo spletnega vprašalnika smo spraševali o stanju na področju kmetijske dejavnosti v občinah, njihovih strateških načrtih na tem področju ter morebitnih pobudah za selitev kmetij na novo lokacijo oziroma njihovo širitev. S pomočjo odgovorov smo prepoznali glavne prostorske izzive kmetijstva ter razmišljali, kako bo na njih odgovorila posodobljena prostorska zakonodaja.

\section{KLJUČNE BESEDE}

prostorsko umeščanje kmetij, prostorska utesnjenost kmetij, prostorski konflikti, prostorska zakonodaja, krajinsko načrtovanje, geografija 


\begin{abstract}
Selecting farm building sites and farm expansion in Slovenia: The legislative framework and experience of Slovenian municipalities

This article provides a critical overview of the existing research and the legislation on selecting sites for farm structures, and it analyzes the experience of spatial planners working at Slovenian municipal offices in implementing this legislation. The analysis is the result of an extensive survey on selecting sites for farm building and resolving related conflicts, in which the experience of 190 Slovenian municipalities was collected. With the help of the online questionnaire we were analyzing the status if agriculture in Slovenian municipalities and strategies for its future development. We also examined the initiatives for relocating, expanding or renovating farm buildings. Based on the answers we identified main agricultural spatial challenges and made reflection on how new updated spatial legislation will address them.
\end{abstract}

\title{
KEY WORDS
}

selecting farm building sites, farms'spatial constraints, spatial conflicts, spatial planning legislation, landscape planning, geography

Uredništvo je prispevek prejelo 8. junija 2017. 


\section{Uvod}

Kmetije so pomemben gradnik kulturne pokrajine, zato lahko s svojo umeščenostjo in videzom bistveno pripomorejo $\mathrm{k}$ njeni prepoznavnosti, $\mathrm{v}$ negativnem smislu pa $\mathrm{k}$ njenemu razvrednotenju. $\mathrm{V}$ drugi polovici 20. stoletja so se v veliki meri izgubila tradicionalna znanja o preudarnem umeščanju objektov in zemljišč v prostor ter funkcionalnim in naravnim razmeram prilagojeni gradnji. Pri tem še zlasti izstopajo: 1) neprimerne lokacije kmetij sredi obdelovalnih zemljišč namesto na njihovem obrobju; 2) njihove dimenzije, kot so prevelike nove stanovanjske stavbe ali gospodarska poslopja prilagojena delu z mehanizacijo; 3) neustrezno oblikovanje oziroma nekritičen prenos značilnih arhitekturnih tipov gradnje $\mathrm{z}$ drugih regij (Fister s sodelavci 1993) ali z urbanih območij. Taki primeri gradnje predstavljajo vizualno motnjo in so pogosto funkcionalno neustrezni ali pa slabšajo delovanje širšega območja naselja. Kot piše Deu (2001) je bilo za podeželsko arhitekturo v starejših obdobjih značilno prilagajanje podnebnim pogojem in pretežna uporaba lokalnih gradbenih materialov. To je prispevalo $\mathrm{k}$ temu, da so se v Sloveniji zaradi geografske raznolikosti (Perko, Hrvatin in Ciglič 2017) razvili jasno prepoznavni regionalni arhitekturni tipi. Upoštevanje naravnih danosti in stavbne tradicije pa se je prekinilo zlasti po drugi svetovni vojni. Takrat so tudi v podeželski arhitekturi začeli uporabljati danemu prostoru neprilagojene materiale in univerzalne stavbne tipe, brez upoštevanja oblikovnih vrednot in meril.

Posledice, ki izhajajo iz umestitve kmetije v določenem prostoru, imajo lahko poleg vizualnih neskladnosti tudi neposreden vpliv na razvoj kmetije. Vse več razvojno perspektivnih kmetij v Sloveniji se sooča s problemom prostorske utesnjenosti znotraj naselij. O njej je govora, kadar kmetije na obstoječi lokaciji ne morejo povečati gospodarskih objektov, da bi posodobile ali razširile svojo dejavnost. Prav tako ne morejo povečati oziroma primerno urediti funkcionalnega prostora na svojem gospodarstvu, ki ga zahteva uporaba sodobne strojne opreme (Perpar in Kovačič 2006). Kmetije so prostorsko lahko omejene zaradi fizičnih dejavnikov, kot so relief, vodotoki, stavbe, prometnice, pa tudi zakonskih predpisov in varovalnih ukrepov, opredeljenih v prostorskih dokumentih (Razpotnik Visković 2015).

Prostorska utesnjenost kmetij zmanjšuje njihov razvojni potencial, saj jim onemogoča širitev, posodobitev kmetijske proizvodnje in otežuje dostopnost do kmetijskih zemljišč (Razpotnik Visković 2017). $\mathrm{S}$ tem vpliva tudi na vprašanje nasledstva na kmetijah, saj je pripravljenost mlajših generacij za kmetovanje odvisna tudi od možnosti prostorske širitve kmetij (Kerbler 2008; Borec s sodelavci 2013; Knežević Hočevar 2013; Knific in Bojnec 2015). V Sloveniji prevladujejo družinske kmetije, kar pomeni, da je na kmetiji poleg proizvodne funkcije pomembna (ali celo najpomembnejša) bivalna funkcija, pogosto pa tudi različne dopolnilne funkcije kot na primer turistična ponudba. Prostorski konflikti imajo tako, zaradi utesnjenosti ali nezdružljivosti s sosednjimi rabami, še večjo težo. Morebitna preselitev kmetije namreč ne pomeni zgolj preselitev dejavnosti na novo lokacijo temveč tudi preselitev v drugo življenjsko in bivalno okolje.

Reševanje nastalih prostorskih konfliktov je naloga prostorskega načrtovanja. Obstoječi zakonodajni okvir nudi možnosti za njihovo odpravljanje, vendar se pomanjkljivosti kažejo na izvedbeni ravni: to so dolgotrajnost postopkov pri iskanju nadomestne lokacije, zapleti pri izdelavi in spremembah prostorskih načrtov in pridobivanju soglasij, neustrezne oblikovne rešitve ter nezaupanje in pomanjkljivo znanje deležnikov.

Poglavitni namen prispevka je pripraviti kritičen pregled obstoječih raziskav in zakonodaje v povezavi $\mathrm{z}$ umeščanjem kmetij v prostor. Poleg tega pa analiziramo tudi izkušnje, $s$ katerimi se pri tem soočajo prostorski načrtovalci v slovenskih občinah. Zaradi močnih pritiskov urbanizacije na eni strani ter vse večjih prostorskih potreb, ki jih imajo kmetijska gospodarstva za širitev in posodobitev svoje dejavnosti, je namreč pričakovati, da se s problemom prostorske utesnjenosti kmetij in njegovim reševanjem sooča večina slovenskih občin.

Analiza je rezultat obsežne raziskave o umeščanju kmetijskih objektov v prostor in reševanju s tem povezanih konfliktov, na podlagi izkušenj 190 slovenskih občin. 


\section{Pregled in analiza dosedanjih raziskav}

Na prostorsko utesnjenost kmetij v slovenskih naseljih, sta kot na pomemben raziskovalni problem opozorila Perpar in Kovačič (2006), saj vpliva na družbene napetosti v naseljih, identiteto podeželske pokrajine in interes mladih za kmetovanje. Avtorja ob tem izpostavljata odgovornost prostorsko-načrtovalske prakse za slabo premišljeno vključevanje kmetijskih zemljišč v zazidljiva območja naselij. To je $\mathrm{z}$ analizo utesnjenosti kmetij na primeru obmestnega naselja v osrednji Sloveniji potrdila tudi Razpotnik Viskovićeva (2011). Vanjo je vključila veljavne občinske prostorske akte za vzorčno naselje ter na podlagi tega ovrednotila možnosti za prihodnji razvoj tamkajšnjih kmetij.

S spreminjanjem demografske strukture na podeželju se povečuje raznolikost interesov različnih skupin prebivalstva, spreminja se njihov sistem vrednot, med njimi pa se stopnjujejo družbene napetosti (Lewis 1998; Golobič, Marušič in Kovačič 2003; Hendreson 2005; Turk Niskač, Klaus in Starec 2010; Smrekar, Šmid Hribar in Erhartič 2016). Vzroki sporov med kmečkimi in nekmečkimi prebivalci so najpogosteje povezani z načinom kmetijske pridelave. Nekatere države oziroma lokalne skupnosti so posledice tovrstnih konfliktov že zaznale (Guštin in Potočnik Slavič 2015). Skušajo jih odpravljati s strožjimi predpisi za kmetijsko dejavnost (Henderson 2005) ali z bolj zaščitniškim odnosom do kmetijstva (Lisanky, Andrews in Lopez 1988).

V zadnjih desetletjih so se raziskave prostorskega razvoja kmetijstva osredotočale na obmestna območja (Berry in Plaut 1978; Lawrence 1988; Errington 1994; Daniels 1999; Kladnik in Petek 2007), saj je kmetijstvo $\mathrm{v}$ neposredni soseščini mest zaradi različnih pritiskov prostorsko bolj ranljivo od kmetijstva na tradicionalnih podeželskih območjih (Cunder 2000; Pažek s sodelavci 2017). Izostrili so se tudi pogledi na vprašanja urbanega kmetijstva (Loherberg s sodelavci 2016).

Strokovnjaki kot ključni problem izpostavljajo prostorsko utesnjenost, ki zmanjšuje razvojni potencial kmetij (Perpar in Kovačič 2006; Razpotnik Visković 2012; 2015), s tem pa tudi zanimanje mladih za kmetovanje. Raziskave dejavnikov, ki vplivajo na uspešno predajo kmetij mlajši generaciji, med drugim izpostavljajo prav možnosti povečanja produktivnosti kmetije (Kerbler 2008; Borec s sodelavci 2013). Problematika prostorske utesnjenosti kmetij je povezana tudi s komasacijami kmetijskih zemljišč. Izkušnje zahodnoevropskih držav z daljšo tradicijo izvajanj komasacij kažejo, da utesnjenih perspektivnih kmetij ni mogoče preseliti, če naselij ne urejamo celostno (Markuszewska 2013).

Drugi večji sklop problemov predstavljajo vprašanja ustreznosti prostorskega umeščanja in oblikovanja kmetijskih objektov. Temelje za njihovo obravnavo je že sredi prejšnjega stoletja s priročnikom Obnova slovenske vasi postavil arhitekt Marjan Mušič (1947) in v njem podrobno predstavil značilnosti (vrednote in merila) grajenih struktur v slovenskih kulturnih pokrajinah ter prikazal možnosti razvoja identitetnih grajenih struktur z upoštevanjem sprememb bivalne kulture in tehničnega napredka, s ciljem: » ..., da bo obnovljena vas boljša in lepša, za kmetsko gospodarjenje in udobno življenje primernejša od stare ..." (Mušič 1947, 141).

Ideji skladne združitve obstoječega, dediščinsko vrednega, s preoblikovanjem in dodajanjem novega so sledile tudi mlajše generacije arhitektov in krajinskih arhitektov (Fister s sodelavci 1993; Lah 1994; Marušič s sodelavci 1998; Deu 2004; Deu 2007). Podajajo nove usmeritve, prilagojene stanju v slovenskem prostoru, saj se zavedajo, da zgolj urejena zakonodaja na tem področju ni dovolj za dvig obstoječe splošne kulture bivanja in zadovoljstva. Kmete in njihov pogled na prihodnji razvoj kmetij in s tem vpliv na prostorske spremembe, je v scenarije razvoja vključila Gantarjeva (2012; 2015). Urejanje prostora je zahtevno in interdisciplinarno delo, ki mora poleg strokovnih priporočil in pobud temeljiti na širši participaciji uporabnikov prostora (Falleth in Hofstad 2008; Gantar in Golobič 2015; Nared s sodelavci 2015).

K aktivnejši politiki usmerjanja razvoja kmetijskih objektov so pristopili tudi v nekaterih krajinskih parkih, kjer so prepoznali izrazit vpliv kmetijstva na oblikovanje varovanih značilnosti in kakovosti prostora, vendar ne zgolj z načinom rabe, temveč tudi s podobo in umestitvijo objektov. Tako je na primer Krajinski park Kozjansko za lastne potrebe izdal več publikacij s podrobnimi analizami značilne arhitekturne tipologije (Deu in Zdovc 2002; Pajer 2013) ter izhodišča za umeščanje in sodob- 
no oblikovanje objektov (Furman Oman, Furman Oman in Sedovnik 2013). Krajinski park Ljubljansko barje pa je s študenti arhitekture pristopil $\mathrm{k}$ iskanju novih ustreznih objektov za shranjevanje senenih in silažnih bal, ki bi bili prilagojeni tradicionalnim arhitekturnim oblikam in sodobnim kmetijskim postopkom.

\section{Metode}

Za predstavitev zakonodajnega okvira za umeščanje kmetijskih objektov v prostor smo pregledali veljavni Zakon o prostorskem načrtovanju (2007) ter druge zakone in strateške dokumente, ki urejajo to področje, kot so Strategija prostorskega razvoja Slovenije (2004), Prostorski red Slovenije (2004), Pravilnik o vsebini, obliki in načinu priprave občinskega prostorskega načrta (2007) ter splošne smernice za pripravo občinskih prostorskih načrtov s področja razvoja poselitve (Splošne smernice ... 2013) in s področja varovanja kmetijskih zemljišč (Splošne smernice ... 2017).

Raziskavo o izkušnjah, s katerimi se pri izvajanju zakonodajnih predpisov soočajo prostorski načrtovalci v slovenskih občinah smo izvedli s kvalitativnim metodološkim pristopom. Na vse slovenske občine smo poslali vprašalnik za strokovne delavce s področja urejanja prostora, ki so se jim po potrebi lahko pridružili še strokovni delavci s kmetijskega ali z drugih področij. Na posamezno občino smo tako prejeli en izpolnjen vprašalnik. V njem smo jih povprašali o: 1) stanju in prihodnjih strateških načrtih občine na področju kmetijstva, 2) morebitnih pobudah za selitev celotnih kmetij, delno selitev, širitev ali prenovo kmetijskih objektov, ki so jih prejeli v zadnjih petih letih, 3) razlogih za pobude in 4) uspešnosti obravnave pobud.

Zaradi velikega števila naslovnikov smo se odločili za samoanketo, za katero je značilna odsotnost anketarja, ki bi nadzoroval anketiranje, postavljal vprašanja in beležil odgovore. Postopek prebiranja in izpolnjevanja je $\mathrm{v}$ tem primeru izključno $\mathrm{v}$ rokah anketiranca, zato smo posebno pozornost namenili izdelavi povabila k reševanju ter oblikovanju vprašanj. Uporabili smo zaprt in kombiniran tip vprašanj, ter vprašanja z mersko lestvico. Dopustili smo možnost, da respondenti sporočijo morebitne komentarje, ki se navezujejo na vsebino vprašalnika. Odločili smo se za spletni vprašalnik in uporabili spletno orodje 1KA (medmrežje 1), ki omogoča takojšnjo in sprotno osnovno analizo dobljenih odgovorov (Polajnar Horvat in Smrekar 2015). Pred objavo spletnega vprašalnika, smo ga testirali v štirih občinah in tako preverili njegovo vsebinsko ter tehnično ustreznost. Vprašalnik je bil zahteven, saj je v petih vsebinskih sklopih vseboval 43 vprašanj (v prispevku predstavljamo le del rezultatov). Kljub njegovi dolžini so se vprašani na občinskih službah nanj odzvali pozitivno. Utesnjenost kmetij in umeščanje kmetijskih objektov $\mathrm{v}$ prostor sta očitno pomembna in aktualna izziva za prostorsko načrtovanje na ravni občin.

\section{Veljavni zakonodajni okvir}

Krovni dokument, ki ureja prostorsko načrtovanje ter umeščanje kmetijskih objektov v prostor, je Zakon o prostorskem načrtovanju (2007). Med poglavitnimi zakonskimi načeli v povezavi z obravnavano tematiko je treba izpostaviti dve: da ima prenova obstoječega prednost pred graditvijo novega ter da se prostorski razvoj prvenstveno usmerja na prosta, degradirana in nezadostno izkoriščena zemljišča znotraj naselij.

Veljavne Strategije prostorskega razvoja Slovenije (2004) se raziskava dotika na dveh ključnih področjih: razvoju slovenske krajine in razvoju poselitve. Strategija določa, da: »... krajino razvijamo kot naravno krajino predvsem na odmaknjenih in ohranjenih območjih, kot kulturno krajino na tradicionalnih kmetijskih območjih, kot urbano krajino v okolici večjih mest in kot kmetijsko intenzivno krajino pa na območjih $z$ visokim pridelovalnim potencialom tal za kmetijsko rabo ...« $(28,2004)$. Razvoj poselitve se usmerja prvenstveno znotraj obstoječih naselij ter znotraj obstoječih gradbenih parcel, vendar tako, 
da se preprečuje navzkrižja med različnimi rabami. Gradnja kmetij zunaj poselitvenih območij je dovoljena, vendar le kadar gre za območja $\mathrm{z}$ visokim pridelovalnim potencialom za kmetijstvo.

Prostorski red Slovenije (2004) določa pravila za urejanje prostora. V navodilih za načrtovanje poselitvenih območij izpostavlja dve pomembni načeli, za umeščanje kmetij v prostor: 1) zagotavljanje sožitja med urbanimi in kmetijskimi funkcijami v podeželskih naseljih, pri čemer imajo kmetijske funkcije $\mathrm{v}$ tradicionalno agrarnih naseljih praviloma prednost, 2) zagotavljanje možnosti za širjenje kmetij oziroma selitev na nepozidana zemljišča, odmaknjena od stanovanjskih objektov. Dokument dodeljuje poseben status razvojno perspektivnim kmetijam, ki se lahko umeščajo zunaj poselitvenih območij, če to zahteva velikost ali proizvodna usmeritev kmetije oziroma potrebe kmečkega gospodinjstva. Prostorski red določa še stopnje izkoriščenosti zemljišč za gradnjo, pri čemer je stopnja v stanovanjskih območjih s kmetijskimi gospodarstvi nižja kot v območjih drugih namenskih rab.

Splošne smernice s področja razvoja poselitve (2013), je pripravilo ministrstvo, pristojno za urejanje prostora. Umeščanja kmetijskih objektov v prostor se neposredno dotikajo v delu splošnih usmeritev razvoja poselitvenih območij podeželskih naselij. Tudi ta dokument izpostavlja: 1) sožitje med funkcijami ter načelno prednost kmetijskih funkcij v tradicionalno agrarnih naseljih, 2) možnost za širjenje večjih kmetij oziroma selitev kmetijskih objektov na nova zemljišča, odmaknjena od stanovanjskih objektov, 3) prenovo omrežij cest in poti za neoviran dostop do gospodarskih dvorišč in obdelovalnih zemljišč. Posebna pozornost je namenjena prenovi naselij. Ta prednostna razvojna usmeritev naj poleg prostorskih ciljev vključuje tudi možnosti za gospodarski razvoj, reševanje družbenih problemov in kakovostnejše bivanje. Dokument natančneje opredeljuje smernice za prenovo kulturne dediščine in druge stavbne dediščine v naseljih, relevantne tudi pri prenovi kmetijskih objektov. Pri umeščanju dejavnosti in prostorskih ureditev želijo upoštevati značilnosti posameznih »krajinskih regij«. Te izhajajo iz njihove rabe, funkcije in podobe kot so naravna ohranjenost, pestrost, harmoničnost, simbolni pomen naravnih in ustvarjenih sestavin prostora. Slediti je treba načelu, da se ohranjajo značilni stik naselij in odprte krajine ter kakovostnih grajenih struktur, vidno privlačni deli krajine ter kakovostni pogledi.

Zakon o kmetijskih zemljiščih (2011) je najprej začasno, s sprejetjem novele leta 2016 pa brez časovnih omejitev (Zakon o spremembah ... 2016) poenostavil postopek gradnje kmetijskih objektov na kmetijskih zemljiščih. Zanjo je zahtevana le priprava občinskega podrobnega prostorskega načrta (v nadaljevanju OPPN) brez predhodnih sprememb namenske rabe v okviru občinskih prostorskih načrtov (v nadaljevanju OPN). Zakon določa dovoljene tipe objektov in predpisuje kriterije za možne investitorje v tovrstnih postopkih. Po novem na kmetijska zemljišča dovoljuje preselitev celotnega kmetijskega gospodarstva, torej tudi njegovih stanovanjskih delov, vendar šele po pridobitvi uporabnega dovoljenja za kmetijske objekte. Na podlagi zakona je Ministrstvo za kmetijstvo, gozdarstvo in prehrano pripravilo Splošne smernice s področja varovanja kmetijskih zemljišč (2017).

Poleg zakonodaje in dokumentov na državni ravni so pomembni tudi dokumenti na občinski ravni. Nekatere večje občine imajo skladno z zakonodajo izdelane strategije razvoja podeželja. Tako na primer Mestna občina Ljubljana s Strategijo razvoja podeželja MOL v programskem obdobju 2014-2020 (2014) $\mathrm{v}$ podeželskem prostoru prepoznava poudarjeno nasprotje med kmetijskimi zemljišči in urbanizacijo, ki se širi tudi na območja, ki so najbolj primerna za kmetijstvo. Obenem izpostavlja kmetijsko dejavnost kot najpomembnejšo za vzdrževanje značilne kulturne pokrajine, ki sega praktično do roba mesta Ljubljane. Poleg opredelitve ciljev, ki temeljijo na spodbujanju razvoja kmetijstva, gozdarstva in povezanih dejavnosti, Strategija vključuje tudi problematiko, ki je povezana s prostorskim načrtovanjem. To je urejanje in širitev kmetij, umeščanje kmetijskih gospodarstev v prostor, opozarjanje na neustrezno opredeljenost objektov in pripadajočih zemljišč ter nujnost obravnave objektov kmetij skupaj s funkcionalnim zemljiščem kot zaokrožene enote urejanja prostora. Občine, ki nimajo samostojnih strategij razvoja podeželja imajo to tematiko načeloma vključeno v strategijo razvoja občine oziroma sorodne dokumente.

Pri načrtovanju in razvoju krajine se na ravni EU oblikujejo novi koncepti in strategije, kot so zelena infrastruktura, ekosistemske storitve, so-naravne rešitve in urbano kmetijstvo. Čeprav so bili ti pristopi že v preteklosti vključeni v slovensko načrtovalsko prakso (le z drugačnim poimenovanjem), še poseb- 
no v okviru krajinskega načrtovanja, prinašajo tudi nove pomembne poudarke in izostrujejo spoznanja o pomenu multifunkcionalnega načrtovanja ter razvoja odprtega prostora in krajine (Šuklje Erjavec 2015; Jovanović, Milanović in Zorn 2017; Polenšek in Pirnat 2017). V tem pogledu je treba razširiti tudi razumevanje načrtovanja območij in objektov kmetij, ki so pomemben soustvarjalec podeželskih, pogosto pa tudi mestnih krajin Slovenije. V zadnjem času se spremembe povezane s tem že odražajo tudi v novih prostorskih razvojnih dokumentih države in občin (na primer predlogi: ZUREP-2, SPRS 2050, Trajnostna urbana strategija mestne občine Kranj). Z večnamenskostjo rabe kmetijskih zemljišč v urbanih in suburbanih okoljih kot tudi v turistično in rekreacijsko usmerjenih predelih podeželja se povečujejo potrebe po gradnji in prenovi kmetijskih objektov. Te naj omogočajo in zagotavljajo razvoj dodatnih dejavnosti kot so prodaja kmetijskih pridelkov in živil na domu, turistični, rekreativni, izletniški, gostinski, družabni in izkustveni programi, nočitve ter predelava lastnih izdelkov za lokalni trg. Po drugi strani se nove potrebe oblikujejo tudi $z$ vidika spodbujanja izrabe obnovljivih virov energije, kar se že kaže v pobudah, kot so izgradnja bioplinarn in namestitev fotovoltaičnih panelov ali vetrnih elektrarn kot novega tipa objektov na kmetijskih zemljiščih.

\section{Analiza izkušenj v praksi - rezultati in razprava}

V obdobju od 1. decembra 2016 do 20 . februarja 2017 se je na vprašalnik pozitivno odzvalo 190 od skupno 212 slovenskih občin, kar predstavlja 92,5\% površja, v njih pa živi 92,4\% prebivalcev Slovenije. Odstotki v nadaljevanju so preračunani na podlagi števila občin, ki so odgovorile na posamezno vprašanje $(\mathrm{n}=100 \%)$.

V Sloveniji prevladujejo podeželske občine, kot take se jih je opredelilo 153. Med občinami, ki so se odzvale na vprašalnik, je tudi vseh 11 mestnih občin.

Pomen kmetijstva se med občinami razlikuje, zato smo v uvodu vprašalnika želeli izvedeti, kolikšen delež kmetij v občini respondenti ocenjujejo kot kmetije z razvojnim potencialom (slika 1). To so aktivne

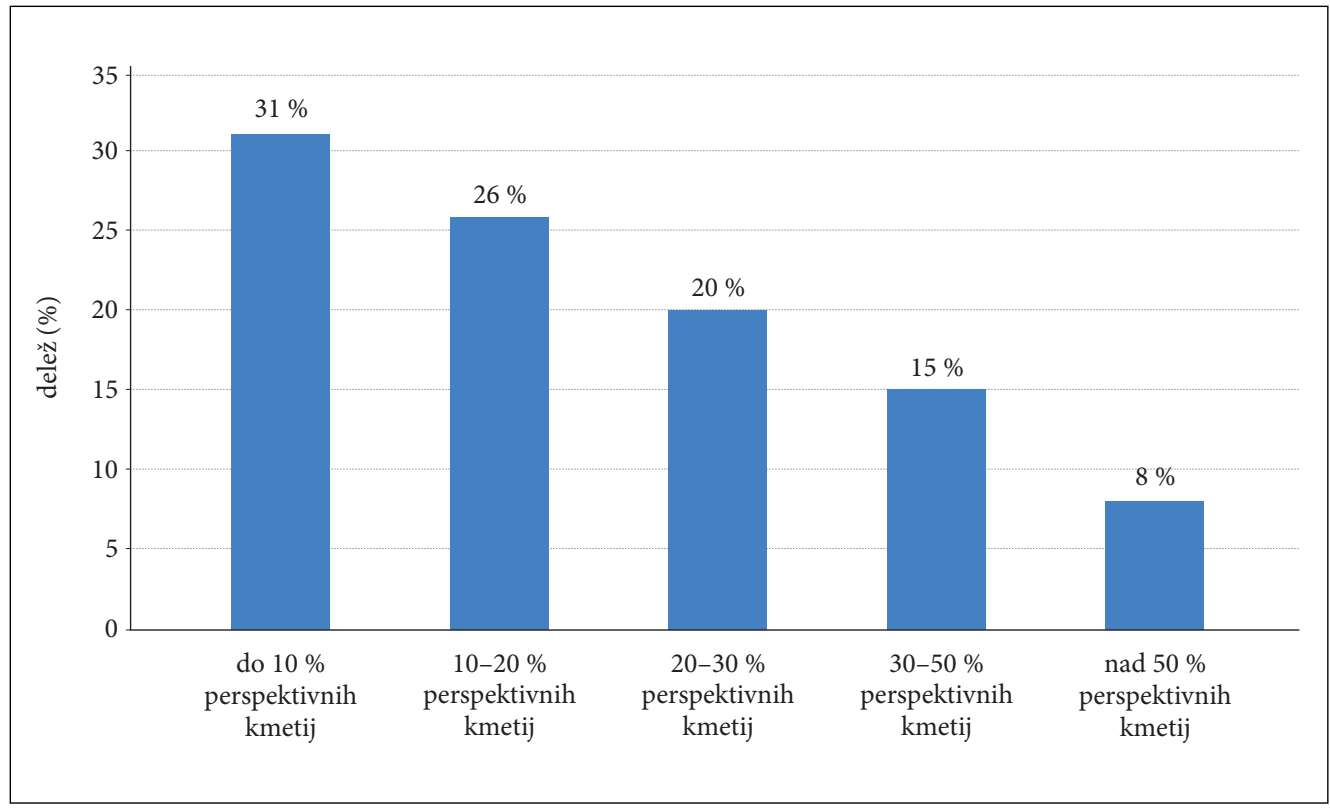

Slika 1: Kolikšen delež kmetij v občini bi ocenili kot kmetije z razvojnim potencialom $(n=187)$ ? 
in finančno uspešne kmetije, ki imajo zagotovljenega naslednika ter po možnosti dobro izobrazbeno sestavo članov kmečkega gospodinjstva.

V več kot $75 \%$ občin ocenjujejo, da je takšnih kmetij manj kot tretjina, v 31 \% občin pa celo, da je kmetij z razvojnim potencialom manj kot desetina (slika 1).

Zanimivo je, da je veliko število mestnih občin opredelilo visok odstotek perspektivnih kmetij, kar je verjetno povezano $\mathrm{z}$ novimi trendi samooskrbe $\mathrm{z}$ lokalno pridelano hrano ( $40 \%$ mestnih občin, ki so odgovorile, sodi v razred $30-50 \%$ oziroma nad $50 \%$ perspektivnih kmetij). V prihodnje bi bilo smiselno raziskati, ali se odnos do reševanja prostorskih problemov kmetij razlikuje glede na to, kakšen je delež razvojno potencialnih kmetij v občini in če, kako? Ali so občine z izrazito nizkim deležem motivirane k spodbujanju kmetijstva, ali morda obratno? Zaradi majhnega deleža je reševanje prostorskih problemov kmetij morda stranskega pomena.

Pri raziskavi nas je zanimalo, ali se kmetije soočajo s problemom prostorske utesnjenosti (slika 2). Temu je pritrdilo $85 \%$ vseh sodelujočih občin, kar potrjuje, da je vprašanje prostorske utesnjenosti kmetij v Sloveniji relevanten in močno razširjen problem. V 28 občinah utesnjenosti kmetij po mnenju respondentov ne zaznavajo; večinoma gre za hribovite in gričevnate občine $\mathrm{z}$ izjemno nizkim deležem razvojno perspektivnih kmetij.

Ob analizi stanja na področju razvojnega potenciala kmetij in njihove prostorske utesnjenosti bi bilo v prihodnje smiselno analizirati strategije razvoja kmetijstva na območjih slovenskih občin, ki so neposredno povezane z lokalno prostorsko politiko. V okviru našega vprašalnika smo se osredotočili le na to, kakšno je načelno stališče občin glede dodatnih možnosti in postopkovne poenostavitve gradnje kmetijskih objektov na kmetijskih zemljiščih, ki jih po letu 2011 prinaša Zakon o kmetijskih zemljiščih in njegove dopolnitve. Na vprašanje, ali občine na strateški ravni podpirajo gradnjo kmetijskih objektov na kmetijskih zemljiščih, jih je pritrdilno odgovorilo $78 \%(n=186)$, preostale pa temu nasprotujejo (slika 3). Do gradnje na kmetijskih zemljiščih so zadržani v štirih mestnih občinah (Maribor, Ptuj, Nova Gorica in Murska Sobota,) ter v številnih občinah z močno razvitim turizmom (Ankaran, Bled, Bohinj, Brda, Tolmin, Zreče, Šmarješke Toplice, Rogaška Slatina). Nasprotno pa so tovrstni gradnji naklonjeni v občinah z višjim deležem razvojno perspektivnih kmetij (Cerklje na Gorenjskem, Vodice, Vrhnika, Mozirje, Sveti Jurij ob Ščavnici).

V raziskavi smo skušali tudi izvedeti, koliko pobud za selitev, širitev ali prenovo kmetijskih objektov so občine obravnavale med letoma 2011 in 2016. Čeprav smo v prvi vrsti želeli pridobiti podatke o številu pobud za spremembo OPPN na podlagi prej omenjenega zakona, smo od respondentov prejeli dokaj raznolike odgovore. Številne občine so v tem obdobju sprejemale OPN-je, ki so krovni prostorsko-načrtovalski akti ali pa so začele postopek njihovega spreminjanja oziroma dopolnjevanja, zato so pobude obravnavali v tem okviru in v vprašalniku navedle njihovo število.

51 občin, ki so vprašalnik izpolnile, števila pobud ni navedlo. Bodisi tovrstnih pobud na občinski ravni niso obravnavali, ali pa respondenti v času reševanja vprašalnikov niso razpolagali z natančnimi podatki o njihovem številu. V preostalih 139 občinah so število pobud navedli, pri čemer so nekateri podali le okvirno oceno števila obravnavanih pobud; na primer med 20 in 30. Zaradi neenotnega razumevanja vprašanja ter razlik med občinami glede na velikost, število kmetij in znotraj tega glede na delež tistih, ki imajo razvojni potencial, ocenjujemo, da so navedbe med seboj težko primerljive. Število pobud namreč variira od 1 do 1700 , zato v nadaljevanju sledi zgolj analiza tipov pobud in razlogov za njihove vloge.

Med tipi pobud (slika 4) so občine najpogosteje izpostavile tiste za širitev kmetije na obstoječi lokaciji (72\%). Kar $35 \%$ občin je obravnavalo tudi pobude za selitev celih kmetij na novo lokacijo. Med tipi pobud, ki so jih respondenti še navedli pod možnostjo »drugo«, so omenjeni obnova stavb, legalizacija že obstoječih objektov, v enem primeru pa tudi ureditev nove kmetije. Primerjava podatkov o tipih

Slika 2: Zaznavanje problema utesnjenosti kmetij in reševanje problema v okviru OPN. Slika 3: Načelna podpora gradnji na kmetijskih zemljiččih za potrebe kmetijske dejavnosti. str. 54 


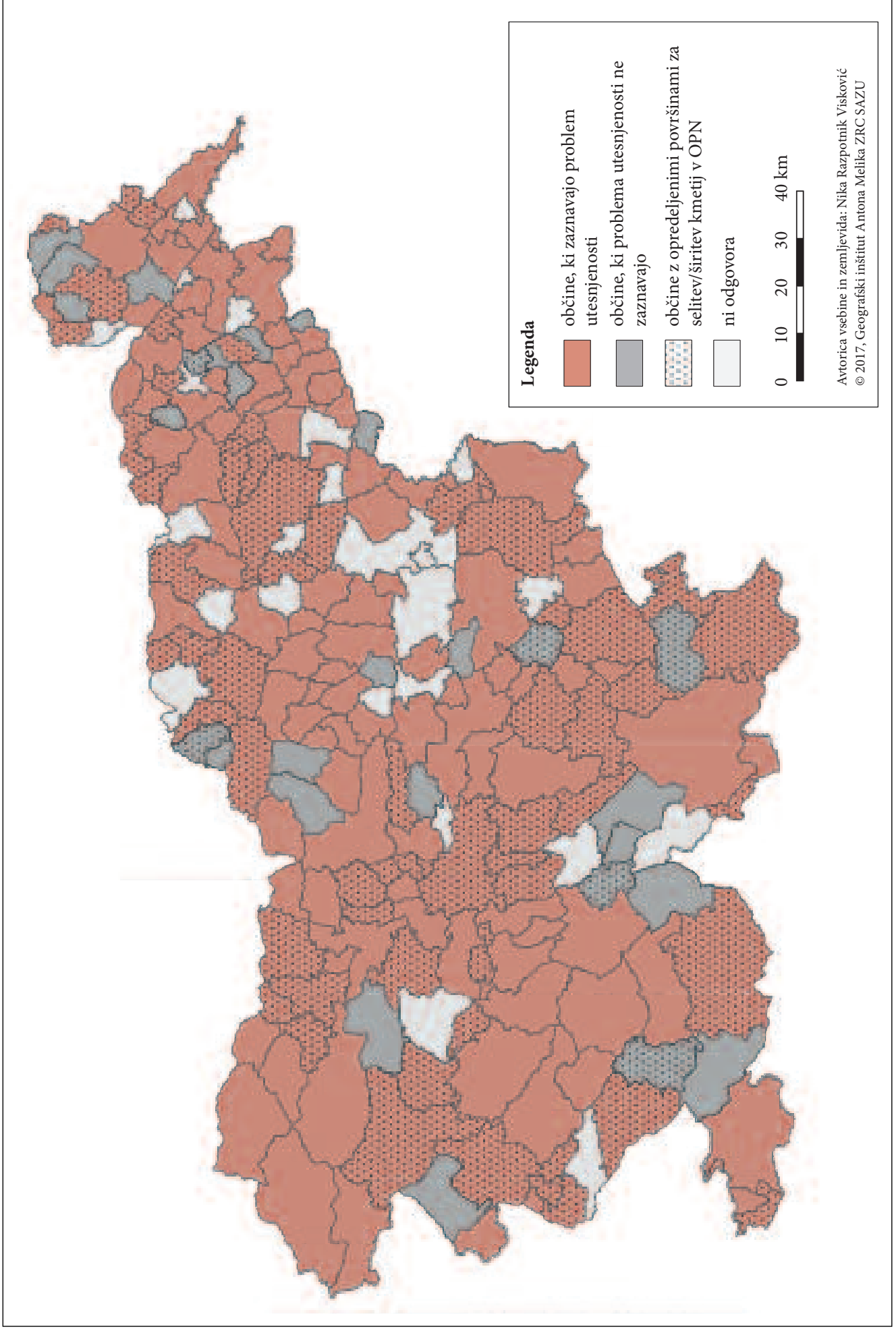




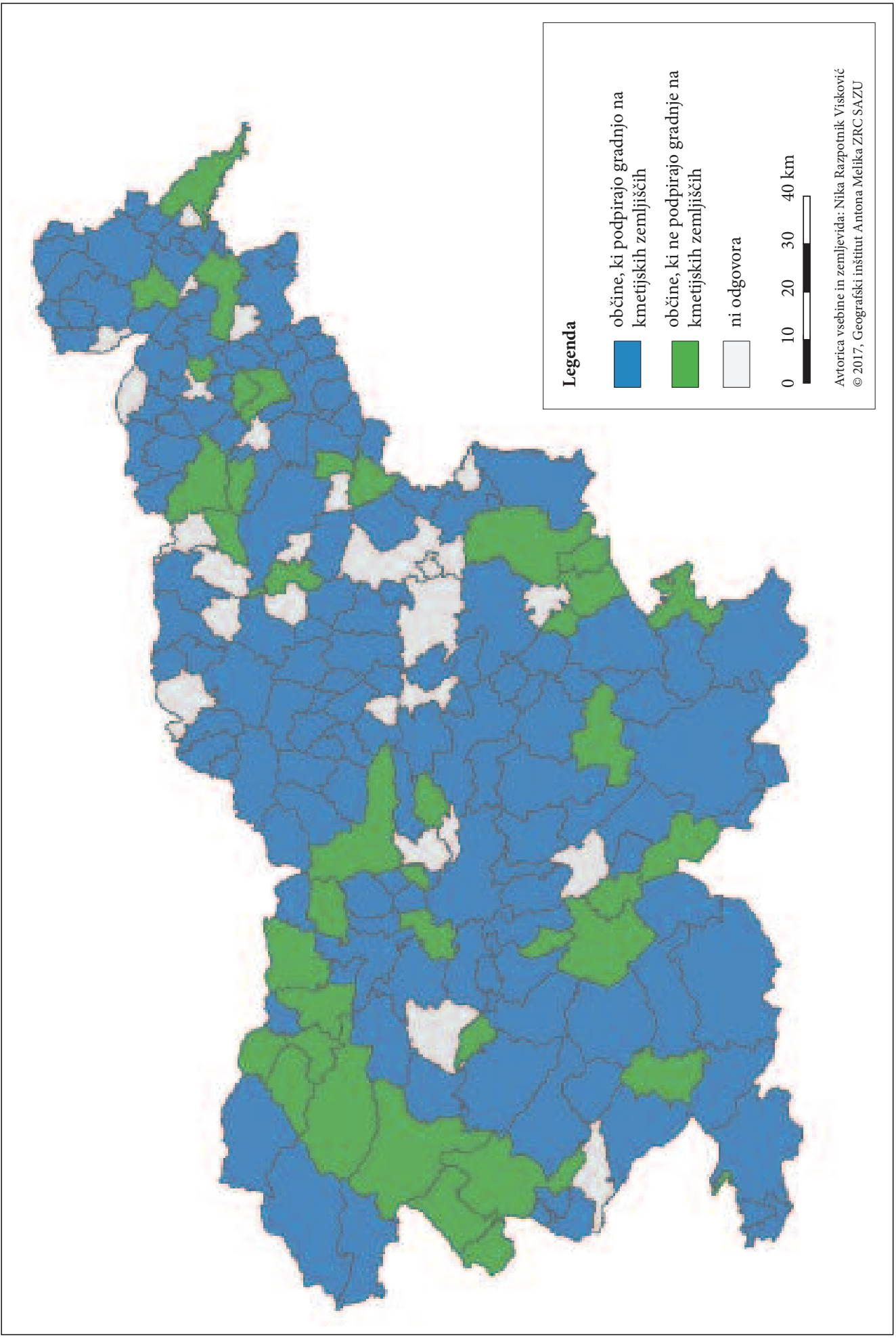




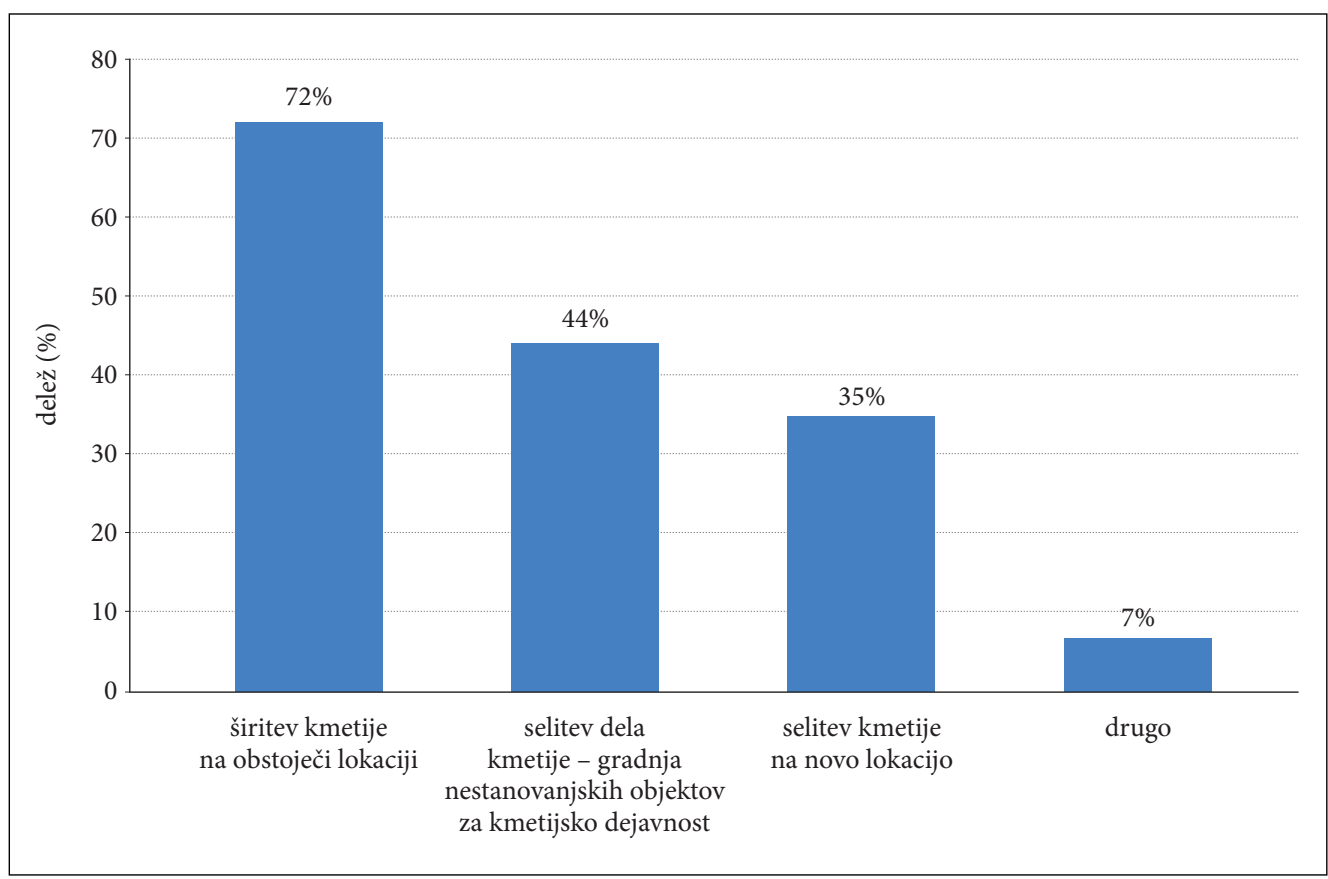

Slika 4: Kakšen je bil tip vloženih pobud $(n=132)$ ?

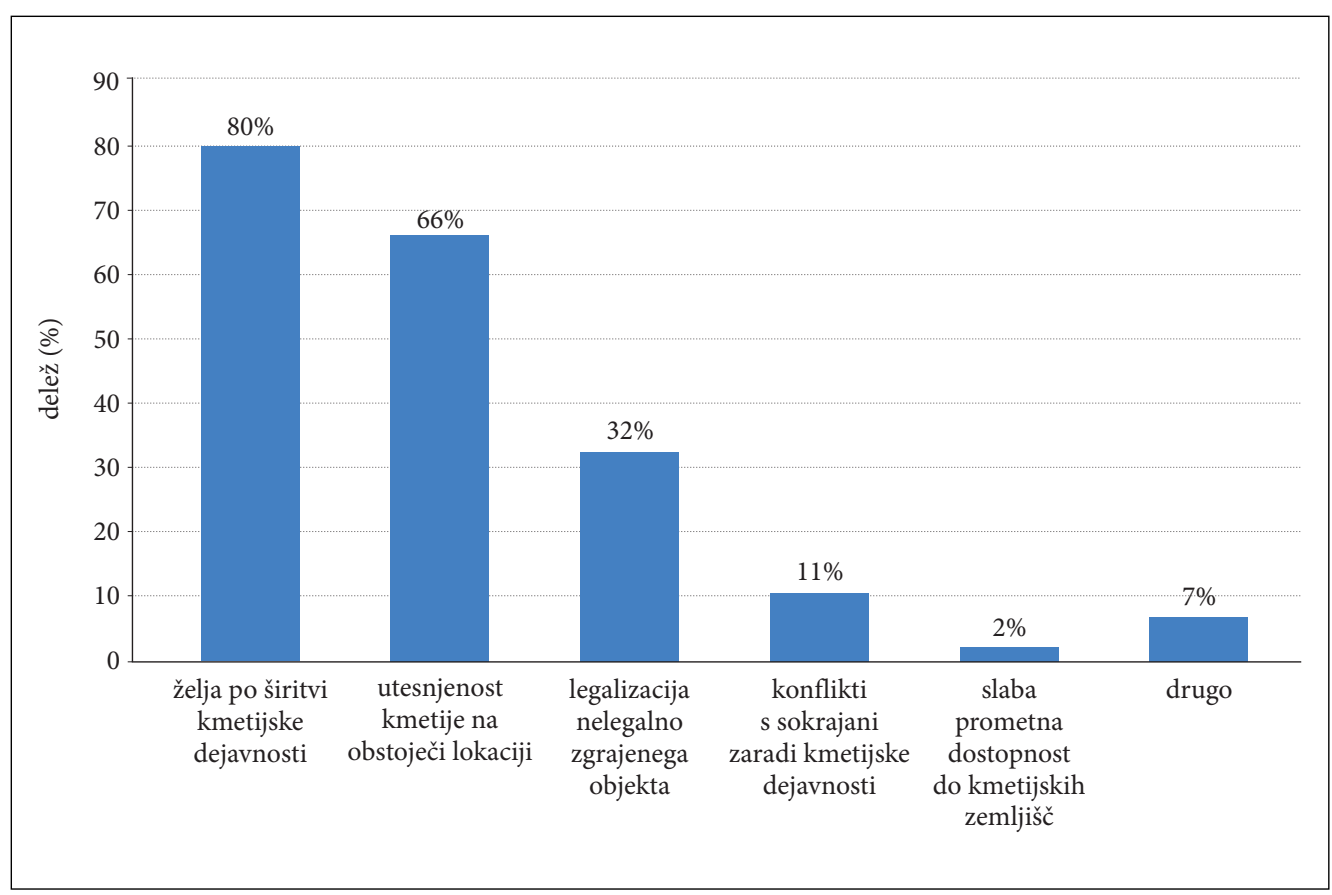

Slika 5: Kakšni so poglavitni razlogi za vložene pobude $(n=132)$ ? 
pobud in deležem razvojno perspektivnih kmetij po občinah pokaže pozitivno povezanost med nizkim deležem perspektivnih kmetij (do $10 \%$ ) ter pobudami za selitev kmetij na novo lokacijo. Gre za posege $\mathrm{z}$ največjim denarnim vložkom in bi jih pričakovali predvsem na območjih $\mathrm{z}$ večjim deležem perspektivnih kmetij.

Med razlogi za vložene pobude (slika 5) so respondenti najpogosteje izpostavili željo po širitvi kmetijske dejavnosti ter utesnjenost na obstoječi lokaciji zaradi urbanizacije in varstvenih režimov. Pri tem smo po pričakovanjih zaznali statistično pomembno pozitivno povezanost med zaznavanjem problema prostorske utesnjenosti kmetij in vloženimi pobudami zaradi tega razloga.

Kakovost vloženih pobud $\mathrm{z}$ vidika umeščanja kmetij v prostor je po mnenju responentov v glavnem ocenjena kot ustrezna. V lestvici od 6 (izjemno ustrezno) do 1 (izjemno neustrezno) jih $35 \%$ pobude ocenjuje kot 5 (večinoma ustrezne), $45 \%$ pa kot 4 (še kar ustrezne). Glavne pomanjkljivosti, ki se pojavljajo v pobudah, so: spreminjanje značaja prostora zaradi neustreznih meril, razmerij in identitete ter prevelika vidna izpostavljenost. Respondenti opozarjajo tudi na preveliko utesnjenost objektov, predvsem zato, ker so pobude vezane na že obstoječe lastništvo predlagatelja.

O primerih zavrnjenih pobud so poročali iz 53 občin, najpogostejši razlog pa je dejstvo, da pobuda ni dobila ustreznih soglasij nosilcev urejanja prostora. V približno dedetina občin so se predlagatelji za umik pobude odločili zaradi prezahtevnih oziroma dolgotrajnih postopkov.

$37 \%$ občin v svojih OPN-jih predvideva območja za selitev oziroma širitev perspektivnih kmetij (slika 2). Glede na to, da je občin, ki zaznavajo problem prostorske utesnjenosti kar $85 \%$, ta rezultat ocenjujemo kot skromnega oziroma nižjega od pričakovanj. Pomen območij predvidenih za selitev oziroma širitev perspektivnih kmetij ni pomemben zgolj z vidika ekonomskega napredka teh kmetij, temveč tudi zaradi zmanjševanja socialnih napetosti znotraj naselij. V slovenskih občinah je slabšanje kakovosti bivanja zaradi kmetijske dejavnosti (na primer hrup, smrad, blato na voziščih) eden izmed glavnih razlogov za nesoglasja med prebivalci v naseljih. Med načini reševanja omenjenih sporov večina občin na prvo mesto postavlja ustrezne prilagoditve v OPN-jih.

V raziskavi so nam respondenti podali tudi svoja opažanja glede zakonodaje, ki ureja umeščanje kmetijskih objektov v prostor. Združimo jih lahko v tri skupine:

1) z vidika kmetov investitorjev so postopki predolgi: postopki sprememb bi se morali prilagoditi razvojnim potrebam aktivnih kmetov, zato je nujno omogočiti hitrejšo ureditev dokumentacije. To še posebej velja za mlade kmete - prevzemnike;

2) določitev ustreznejših kriterijev za to, kdo lahko gradi na kmetijskih zemljiščih (različna stališča): po mnenju nekaterih respondentov so trenutni pogoji za investitorje prezahtevni, kar je še posebej problem v občinah z nizkim deležem aktivnih in razvojno perspektivnih kmetij. Nekateri respondenti se zavzemajo za zaostritev pogojev, da se s tem zagotovi dolgoročna kmetijska namembnost zgrajenih objektov;

3) prostorski izzivi sodobne kmetijske proizvodnje: sodobno kmetijsko gospodarstvo je danes tako zahtevno, da se težko vključuje v obstoječa naselja, kar terja razmislek o konceptu prostorskega ločevanja kmetijskih gospodarstev od preostale (predvsem stanovanjske) pozidave.

\section{Sklep}

Namen prispevka je pregled obstoječe slovenske zakonodaje s področja umeščanja kmetij v prostor in analiza izkušenj, ki jih imajo prostorski načrtovalci po občinah v Sloveniji pri njenem izvajanju. Področje umeščanja kmetijskih objektov v prostor urejajo zakoni, strategije, prostorski red in smernice, ki so obvezna izhodišča za občinske prostorske načrte in občinske podrobne prostorske načrte. Širjenje kmetij izven poselitvenih območij zakonodaja dopušča zgolj tistim s statusom razvojno perspektivnih kmetij. Po ocenah občinskih strokovnih delavcev je v treh četrtinah slovenskih občin njihov delež manjši od ene tretjine, v $31 \%$ občin pa manjši od desetine. 
Nov Zakon o urejanju prostora (ZUreP-2, osnutek 2016), ki je trenutno v fazi usklajevanja, bo razveljavil in nadomestil prejšnji krovni zakon. V novem zakonskem predlogu se širitve oziroma posegi, ki veljajo za kmetijske objekte, ne bodo omejevali na vidik perspektivnosti kmetije, temveč na pogoje za dopuščanje dopolnilne gradnje v naseljih, kot sta ohranjanje in dopolnjevanje posamične poselitve in načrtovanje prostorskih ureditev v drugih ureditvenih območjih. Pri dopolnjevanju posamične poselitve naj bi bila možna dopolnilna gradnja novih objektov, ki so potrebni za izvajanje kmetijske in dopolnilnih dejavnosti na kmetiji ter dopolnilna gradnja novih stanovanjskih objektov, če gre za vprašanje obstoja kmetije in tega ni mogoče zagotoviti v okviru kapacitete obstoječih stavb. Ali bodo predvidene spremembe odgovorile na resnične potrebe razvoja kmetijstva in urejanja kakovostnega bivanja vseh prebivalcev v naselju, pa bo pokazalo šele njegovo izvajanje v praksi?

Zahvala: Delo je bilo delno financirano v okviru ciljnega raziskovalnega projekta Umeščanje kmetijskih objektov $v$ krajino in reševanje prostorskih konfliktov (V6-1629), ki ga financirata Ministrstvo za kmetijstvo, gozdarstvo in prehrano ter Javna agencija za raziskovalno dejavnost Republike Slovenije.

\section{Viri in literatura}

Berry, D., Plaut, T. 1978: Retaining agricultural activities under urban pressures: a review of land use conflicts and policies. Policy Sciences 9-2. DOI: https://doi.org/10.1007/BF00143740

Borec, A., Bohak, Z., Turk, J., Prišenk, J. 2013: The succession status of family farms in the Mediterranean region of Slovenia. Sociológia 45-3.

Cunder, T. 2000: Sedanje stanje in razvojne možnosti kmetijstva. Ljubljana - Geografija mesta. Ljubljana. Daniels, T. 1999: When city and country collide: Managing growth in the metropolitan fringe. Washington D.C. Deu, Ž. 2001: Stavbarstvo slovenskega podeželja: Značilno oblikovanje stanovanjskih hiš. Ljubljana.

Deu, Ž. 2004: Prenova stavb na slovenskem podeželju. Ljubljana.

Deu, Ž. 2007: Ozemeljska raznovrstnost - cilj sodobnega urejanja prostora. Geodetski vestnik 51-2.

Deu, Ž., Zdovc, H. 2002: Od načrta do stavbe: arhitektura Kozjanskega v načrtih in dokumentih iz srede 19. stoletja. Zgodovinski arhiv Celje in Javni zavod Kozjanski park. Podsreda.

Errington, A. 1994: The peri-urban fringe: Europe's forgotten rural areas. Journal of Rural Studies 10-4. DOI: https://doi.org/10.1016/0743-0167(94)90046-9

Falleth, E., Hofstad, H. 2008: Rural response to urban-biased land use policy - New bottom-up planning strategies in Norway. European Journal of Spatial Development 30.

Fister, P., Boh-Pečnik, N., Debevec L., Deu, Ž., Kavčič, M., Lah, L. 1993: Arhitekturne krajine in regije. Ministrstvo za okolje in prostor, Urad za prostorsko planiranje. Ljubljana.

Furman Oman, G., Furman Oman, M., Sedovnik, J. 2013: Sodobna arhitekturna tipologija na Kozjanskem. Podsreda.

Gantar, D. 2012: Tipi scenarijev in njihova uporaba v prostorskem načrtovanju. Geodetski vestnik 56-3. DOI: https://doi.org/10.15292/geodetski-vestnik.2012.03.499-512

Gantar, D. 2015: Pričakovanja kmetov o spremembah kulturne krajine na območju občine Idrija. Annales, Series historia et sociologia 25-1.

Gantar, D., Golobič, M. 2015: Landscape scenarios: a study of influences on attitudes and actions in a rural landscape. Futures 69. DOI: https://doi.org/10.1016/j.futures.2015.02.002

Golobič, M., Marušič, I., Kovačič, M. 2003: Možnosti za usklajevanje razvoja kmetijstva z drugimi družbenimi interesi na slovenskem podeželju, primer občine Komenda. Kmetijstvo 81-2.

Guštin, Š., Potočnik Slavič, I. 2015: Prepoznavanje in prostorska razmestitev konfliktov na podeželju. Geografski vestnik 87-1. DOI: https://doi.org/10.3986/GV87105

Henderson, S. R. 2005: Managing land-use conflict around urban centres: Australian poultry farmer attitudes towards relocation. Applied Geography 25. DOI: https://doi.org/10.1016/j.apgeog.2005.03.001 
Jovanović, M. M., Milanović, M. M., Zorn, M. 2017: The use of NDVI and CORINE Land Cover databases for foresta management in Serbia. Acta geographica Slovenica 58-1. DOI: https://doi.org/10.3986/ AGS.818

Kerbler, B. 2008: The influence of factors of the socio-geographical structure of mountain farms in Slovenia upon farm succession statuses and decisions. Acta geographica Slovenica 48-2. DOI: https://doi.org/10.3986/AGS48203

Kladnik, D., Petek, F. 2007: Kmetijstvo in spreminjanje rabe tal na Ljubljanskem polju. Geografski vestnik 79-2.

Knežević Hočevar, D. 2013: Etnografija medgeneracijskih odnosov. Dom in delo na kmetijah skozi življenjske pripovedi. Ljubljana.

Knific, K., Bojnec, Š. 2015: Structural changes in land use of agricultural holdings in hilly rural areas. Acta geographica Slovenica 55-2. DOI: https://doi.org/10.3986/AGS.736

Lah, L. 1994: Prenova stavbne dediščine na podeželju - Kras. Novo mesto.

Lawrence, H. W. 1988: Changes in agricultural production in metropolitan areas. Professional Geographer 40-2. DOI: https://doi.org/10.1111/j.0033-0124.1988.00159.x

Lewis, G. 1998: Rural migration and demographic change. The Geography of Rural Change. Harlow.

Lisansky, J., Andrews, M. S., Lopez, R. A. 1988: The determinants of right-to-farm conflicts. Rural Sociology 53-2.

Loherberg, F., Lička L., Scazzosi, L., Timpe, A. (ur) 2016: Urban Agriculture Europe. Berlin.

Markuszewska, I. 2013: Land consolidation as an isntrument of shaping the agrarian structure in Poland. Quaestiones Geographicae 32-3. DOI: https://doi.org/10.2478/quageo-2013-0027

Marušič, I., Jančič, M., Bartol, B., Prem, M. 1998: Regionalna razdelitev krajinskih tipov v Sloveniji Metodološke osnove. Ministrstvo za okolje in prostor, Urad Republike Slovenije za prostorsko planiranje. Ljubljana.

Medmrežje 1: https://www.1ka.si (30.5.2017).

Mušič, M. 1947: Obnova slovenske vasi. Celje.

Nared, J., Razpotnik Visković, N., Cremer-Schulte, D., Brozzi, R., Cortines Garcia, F. 2015: Achieving sustainable spatial development in the Alps through participatory planning. Acta geographica Slovenica 55-2. DOI: https://doi.org/10.3986/AGS.1631

Pajer, A. 2013: Temelji graditeljske prepoznavnosti. Podsreda.

Pažek, K., Irgolič, A., Turk, J., Borec, A., Prišenk, J., Kolenko, M., Rozman, Č. 2017: Multi-criteria assessment of less favoured areas: a state level. Acta geographica Slovenica 58-1. DOI: https://doi.org/ 10.3986/AGS.962

Perko, D., Hrvatin, M., Ciglič, R. 2017: Determination of landscape hotspots of Slovenia. Acta geographica Slovenica 57-1. DOI: https://doi.org/10.3986/AGS.4618

Perpar, A., Kovačič, M. 2006: Prostorski vidiki razvoja kmetij. Dela 25. DOI: https://doi.org/10.4312/ dela.25.5.61-71

Polajnar Horvat, K., Smrekar, A. 2015: Veljavnost osebnega in spletnega anketiranja v geografskem raziskovanju. Geografski vestnik 87-2. DOI: https://doi.org/10.3986/GV87208

Polenšek, M., Pirnat, J. 2017: Forest patch connectivity: The Case of the Kranj-Sora Basin, Slovenia. Acta geographica Slovenica 58-1. DOI: https://doi.org/10.3986/AGS.3001

Pravilnik o vsebini, obliki in načinu priprave občinskega prostorskega načrta ter pogojih za določitev območij sanacij razpršene gradnje in območij za razvoj in širitev naselij. Uradni list Republike Slovenije 99/2007. Ljubljana.

Prostorski red Slovenije. Uradni list Republike Slovenije 122/2004. Ljubljana.

Razpotnik Visković, N. 2011: Spatial limitations on farms in urban outskirts. Acta Geographica Slovenica 51-1. DOI: https://doi.org/10.3986/AGS51105

Razpotnik Visković, N. 2012: Vloga mešanih kmetij v gospodarski, okoljski in prostorski preobrazbi obmestij. Doktorsko delo, Fakulteta za gradbeništvo in geodezijo Univerze v Ljubljani. Ljubljana. 
Razpotnik Visković, N. 2015: Evaluating the development potential of farms on urban outskirts: methodology. Acta geographica Slovenica 55-1. DOI: https://doi.org/10.3986/AGS.704

Razpotnik Visković, N. 2017: Spatial constraints of Slovenian farms: What does urbanization have to do with it? European Countryside 9-2. DOI: https://doi.org/10.1515/euco-2017-0017

Smrekar, A., Šmid Hribar, M., Erhartič, B. 2016: Stakeholder conflicts in the Tivoli, Rožnik Hill, and Šiška Hill protected landscape area. Acta geographica Slovenica 56-2. DOI: https://doi.org/10.3986/ AGS.895

Splošne smernice s področja razvoja poselitve. Ministrstvo Republike Slovenije za infrastrukturo in prostor. Ljubljana, 2013. Medmrežje: http://www.mop.gov.si/fileadmin/mop.gov.si/pageuploads/podrocja/ dpn/smernice/usmerjanje_poselitve.pdf (23.2.2017).

Splošne smernice s področja varovanja kmetijskih zemljišč. Ministrstvo za kmetijstvo, gozdarstvo in prehrano. Ljubljana, 2017. Medmrežje: http://www.mkgp.gov.si/fileadmin/mkgp.gov.si/pageuploads/ podrocja/Kmetijstvo/Kmetijska_zemljisca/splosne_smernice_februar_2017.pdf (23.2.2017).

Strategija prostorskega razvoja Slovenije. Uradni list Republike Slovenije 76/2004. Ljubljana.

Strategija razvoja podeželja Mestne občine Ljubljana v programskem obdobju 2014-2020. Mestna občina Ljubljana. Ljubljana, 2014. Medmrežje: https://www.ljubljana.si/assets/Uploads/1-Strategija-razvoja-podezelja-Mestne-obcine-Ljubljana-za-programsko-obdobje-2014-2020.pdf (12.4. 2017)

Šuklje Erjavec, I. 2015: The importance of a comprehensive planning approach to green infrastructure. Green infrastructure in Central, Eastern, and South-Eastern Europe: is there a universal solution to environmental and spatial challenges? Ljubljana.

Turk Niskač, B., Klaus, S., Starec, S. 2010: Urbano življenje ob kmetijah ali ruralno življenje ob stolpnicah? Dilema jasne ločnice med urbanim in ruralnim. Urbani izziv 21-1. DOI: https://doi.org/ 10.5379/urbani-izziv-2010-21-01-00

Zakon o kmetijskih zemljiščih. Uradni list Republike Slovenije 71/2011. Ljubljana.

Zakon o prostorskem načrtovanju. Uradni list Republike Slovenije 33/2007. Ljubljana.

Zakon o spremembah in dopolnitvah Zakona o kmetijskih zemljiščih. Uradni list Republike Slovenije 27/2016. Ljubljana.

Zakon o urejanju prostora (ZUreP-2) - osnutek. Ministrstvo za okolje in prostor. Ljubljana, 2016. Medmrežje: http://www.mop.gov.si/fileadmin/mop.gov.si/pageuploads/osnutki/zurep.docx (30.5.2017).

\section{Summary: Selecting farm building sites and farm expansion in Slovenia: The legislative framework and experience of Slovenian municipalities} (translated by DEKS d. o. o.)

This article provides a critical overview of the existing research and the legislation on selecting sites for farm structure, and it analyzes the experience of spatial planners working at Slovenian municipal offices in implementing this legislation. The analysis is the result of an extensive survey on selecting farm building sites and resolving related conflicts, in which the experience of 190 Slovenian municipalities was collected.

To present the legislative framework for selecting sites for farm structures, the applicable Spatial Planning Act and other acts and strategic documents governing this area (e.g., the Spatial Development Strategy of Slovenia, the Spatial Planning Rules of Slovenia, the Rules on the Content, Form, and Methods of Preparing Municipal Spatial Plans, and the general guidelines for preparing municipal spatial plans related to settlement and agricultural land development) were reviewed.

The analysis of the experience gained by spatial planners at Slovenian municipal offices was carried out using a qualitative method. A questionnaire for spatial planning specialists was sent to all Slovenian municipal offices; where necessary, specialists in agriculture or other areas were also included in the survey. 
From December 1st, 2016 to February 20th, 2017, 190 of the total of 212 Slovenian municipalities (accounting for $92.5 \%$ of Slovenian territory and $92.4 \%$ of the total Slovenian population) responded to the questionnaire. The percentages presented below are calculated based on the number of municipalities that responded to an individual question.

The survey examined whether Slovenian farmers have to deal with the issue of spatial constraints. This was confirmed by $85 \%$ of all of the participating municipalities, which proves that spatial constraints on farms is a relevant and widespread issue in Slovenia. In twenty-eight municipalities, the respondents did not report any spatial constraints; this mainly included the hilly municipalities with an exceptionally low share of farms with development potential.

In addition to analyzing the farms' development potential and their spatial constraints, in the future it would also make sense to analyze the strategies for agricultural development in Slovenian municipalities that are directly connected with the local spatial policy. The questionnaire used in the survey described focused only on the municipalities' general stance on the additional opportunities and simplified procedures for building farm buildings on agricultural land that have been made possible by the Agricultural Land Act and its amendments since 2011. Seventy-eight percent of municipalities confirmed that they strategically supported the construction of farm buildings on agricultural land, and the rest were against it.

The survey also examined the number of initiatives for relocating, expanding or renovating farm buildings that the municipalities processed between 2011 and 2016, and the purpose of the initiatives submitted. Fifty-one municipalities that filled out the questionnaire did not provide the number of these initiatives. The remaining 139 municipalities stated the number, whereby some only provided an approximate number of the initiatives processed.

The types of initiatives most frequently highlighted by the municipalities included those for expanding farm buildings at an existing site (72\%); as many as 35\% of municipalities also handled initiatives for moving entire farms to a new location. The »other « types of initiatives listed included building renovation, legalization of existing structures, and in once case also the construction of new farm buildings. A comparison of the information on the types of initiatives and the share of developmentally promising farms by municipality shows a positive correlation between the low share of promising farms (up to $10 \%$ ) and the initiatives for moving farms to a new location. These changes demand the highest financial investment and would primarily be expected in areas with a large share of promising farms.

The reasons for the initiatives submitted that the respondents most frequently provided included the desire to expand their agricultural activity and the spatial constraints of the existing location due to urbanization and protection regimes. As anticipated, there was a statistically significant correlation between perceiving the problem of the farms' spatial constraints and the initiatives submitted for this reason.

Thirty-seven percent of the municipalities have allocated areas for relocating or expanding promising farms in their municipal spatial plans. Considering that as many as $85 \%$ of the municipalities acknowledge a spatial constraint problem, this share is modest and lower than expected. The areas envisaged for relocating or expanding promising farms are important not only from the viewpoint of these farms' economic progress, but also in terms of reducing social tensions within settlements. Lower quality of life due to agricultural activity (noise, odors, mud on the roads, and so on) in Slovenian municipalities is one of the main reasons for disagreement among residents. The majority of municipalities consider suitable adjustments in their spatial plans to be the primary method for resolving such disputes.

The selection of farm building sites is governed by the relevant laws, strategies, spatial planning rules, and guidelines that form the mandatory bases for general and detailed municipal spatial plans. The law only allows farm expansion beyond existing settled areas if the farm has the status of a developmentally promising farm.

The new Spatial Planning Act (Sln. Zakon o urejanju prostora or ZUreP-2, 2016 draft), which is currently still in the stage of harmonization, will rescind and replace the former umbrella act. According 
to the new bill, expansions or changes relating to farm buildings will not be limited to the farm's development potential, but to the conditions allowing additional construction in settlements, such as maintaining and expanding an individual built-up area outside the core settlement, and spatial planning in other planning zones. With regard to expanding individual built-up areas outside the main settlements, the new law will allow additional construction of new structures required for carrying out agricultural and secondary activities on the farm as well as additional construction of new residential buildings if the farm's existence is at stake and this cannot be ensured by the capacity of the current buildings. However, practical implementation will show whether the envisaged changes will meet the real needs of agricultural development and offering a quality life for all residents in a settlement. 